\title{
Organizational and Legal Foundations of the Creation and Functioning of Collaborations
}

\author{
Larisa Yu. Aisner \\ Krasnoyarsk State Agriculture University, \\ Russia \\ larisa-ajsner@yandex.ru
}

\author{
Elena N. Sochneva \\ Siberian Federal University \\ Russia \\ sochneva.e@inbox.ru
}

\author{
Mikhail Chervyakov \\ Krasnoyarsk State Agriculture University \\ Russia
}

\begin{abstract}
In the modern world, a new socio-economic phenomenon has appeared - a collaboration, which is understood as the association of two or more persons for the joint implementation of innovative directed activities in the form of a project. And although this phenomenon appeared relatively recently, however, in practice, such associations have been present in the economy for a long time. These included innovative public-private partnerships, and technology parks, and strategic scientific alliances, etc. There are many types and forms of collaboration in which there are both legal entities and individuals. The collaboration differs significantly from the usual organization, and, first of all, in that its participants share a common goal, and informal relationships prevail within the collaboration. A collaboration on content in terms of institutional theory is a relational contract for interspecific resources. That is, we are talking about a contract based on which there are no legal relations, or they are minimized, and its resources (that is, people) are mutually unique and complementary. However, collaboration may not always exist outside the legal field. International collaborations and collaborations between business units should be based on a contractual relationship, which reflects the principles of sharing the benefits and attributing costs. This is the object of contracts between the participants in the collaboration.
\end{abstract}

Keywords: collaboration, association, intellectual human capital, resources, efficiency, innovation, legal framework, distribution

\section{INTRODUCTION}

Modern business places strict conditions for functioning, which leads to various associations of economic entities in order to achieve the maximum possible efficiency. One of the forms of such associations is collaboration, which is a joint activity of two or more people, as a result of which there is the exchange of knowledge, experience and skills in order to obtain shared benefit.
Foreign in origin, the concept of "collaboration" goes back to the Latin "collaborare" - cooperation, work with someone. From the dead language it migrated to the living and elegant French: here "collaborateur" is a collaborator, co-author, colleague, colleague [1].

Associations of people to achieve goals have always existed, but collaboration is a special association peculiar to modern society. It is the source of new business processes, training and growth of human capital of participants. Collaborations are created for the purpose of creating and transferring innovations, and precisely this features distinguishes them from ordinary associations of people or organizations.

Most often, the term "collaboration" is used in academia, when two or more scientists begin to work on one idea and exchange knowledge and experience among themselves [2].

Let us consider the essence and main forms of existence of collaborations in the modern economy.

\section{Literature ReVIEW AND RESEARCH MethodS}

Methods of analysis and synthesis, comparative analogy, method of logical research, institutional analysis were used to write the work. Since creation of a collaboration involves the exchange of resources, it is advisable to consider the collaboration from the point of view of the resource approach. From this point of view, scientists G. Olson, A. Zimmerman and N. Bos of the University of Massachusetts define a collaboration as an organizational association of scientists "that includes researchers from different organizations (and different countries), supports extensive and repetitive human interaction focused on a common field of study, and provides access to the data sources, exhibits, and tools required to accomplish a research task." [3]. Many modern scientists abroad consider collaboration, first of all, as a form of 
effective research cooperation leading to a synergistic effect by attracting human capital from different organizations, fields and even countries [4;5].

Researchers A. Thomson and J. Perry consider collaborations in terms of organizational and process approaches. In accordance with the process approach, the collaboration activity is considered as a set of processes. In accordance with the organizational approach, the authors define collaboration as the highest, interactive form of cooperation. Collaboration is also understood as "the process of formal and informal coordination between autonomous players, during which they create joint rules and organizations to regulate their interactions and activities or solve tasks that unite them" [6]. In continuation of the above, the author N. V. Smorodinskaya notes that these joint rules are shared by all participants, bringing them mutual benefits, and the agreements themselves can occur continuously [7]. In the process of activity, the members of the collaboration constantly exchange knowledge, coordinate their decisions and coordinate their actions [8].

At the international level, collaborations are considered as associated economic entities operating based on multilateral cooperation of states and / or private companies for the targeted implementation of their main and subsidiary projects. The result of the implementation of projects because of collaboration is a specific object of collective use and ownership, generating commodity objects and bringing effects in the market implementation at the mega-level of the global economic system [9].

It is important to note that collaborations are the product of the knowledge economy. According to N. V. Smorodinskaya, collaboration is a form of cooperation suitable for the knowledge economy. Collaborations differ in subjects and objects, levels and scales, spheres and industries, sectors and segments, provide both intensive and extensive development of the existing technological structure, creating fundamentally new types of goods and services [10].

Collaborations are characterized by a synergistic effect in their activities and participants of collaborations cooperate with this purpose, otherwise they could work alone [11].

Previously, there were also and still are various other forms of associations, ranging from business firms and ending with public associations; but today we are increasingly talking about collaboration as the most effective form of association of participants, as it is based on the exchange of knowledge and practices [12].

One of the characteristics, and to some extent one of the benefits, of collaboration is that the collaboration operates in a more informal setting than the usual firm. A firm in institutional Economics is treated as a bundle of informal contracts (implicit) concerning interspecific resources [13]. This means that it is not necessary to formalize the relationship in order to function within the firm in order to obtain benefits. Moreover, the more formal the relationship, the less likely it is to create a collaboration, since formal relationships put the fulfillment of formal obligations in the foreground, rather than mutual benefit. However, it is impossible to completely neutralize the influence of legal factors, so it is important to understand the role played by legal aspects in the activities of collaborations.

\section{RESULTS}

Today, collaborations exist in all sectors and spheres of activity, especially where intellectual work is needed.

According to the organizational form, collaborations can be divided as follows.

1. Collobaration within a formally functioning organization. The combination of connections in it is unpredictable and spontaneous. Its participants are people close in spirit and have similar interests. At some stage of communication, they can be united by a common goal, and they will create a collaboration.

2. Collaboration between several organizations. Such collaboration usually functions to implement a project or maintain a business. Examples include various conglomerates, concerns, industrial groups and other associations associated with an innovative idea.

3. Collaboration between employees of different organizations. An example is social networks that bring together professionals in an industry or any other employers ' associations.

4. Collaboration between organizations from different countries. It is necessary to create a joint product by combining the resources of different countries.

5. Collaboration between government and business (innovative public-private partnership). If the purpose of such association is to create a unique product or service, then it also applies to collaborations.

In collaboration, of course, there is a problem of intellectual labor management. The subjects of collaboration are representatives of highly intellectual capital, which is effective in case of competent management and can lead to destructive consequences in case of inefficient management [14].

Consider the distinctive features of collaboration and standard organization.

In a conventional organization model, the use of intellectual capital can have a twofold effect: either a superpositive effect or a super-negative effect. This is due to the fact that highly qualified personnel are difficult to manage. Such an employee can lead the organization to great success, but for this his or her goals must coincide with the goals of the organization, and not go against the grain. In addition, for the effective functioning of such employee, it is necessary to use the techniques of intangible motivation along with material, so that the latter always has a desire to give his or her human capital.

In collaboration, where the basis of the interaction of the participants is a partnership, highly intellectual capital has only a positive effect. 
The above indicates that in many collaborations the contracts binding its private owners are purely formal (excluding international collaborations, where officially established relations are necessary, taking into account private international law).

The goals of the collaboration are the link for its creation and construction, and in the normal organization, the goals are set by its founders, and may not be shared by its employees.

Thus it is necessary to understand that the purposes of activity of any organization consist in maintenance of its current activity, and the purpose of the collaboration is creation of something unique and inimitable [17].

\section{DISCUSSION}

The formalized part of the process of management of Collaboration, in fact, can be interpreted more broadly than an ordinary organization. From the point of view of the modern economy, such associations as technoparks, technological platforms, strategic alliances, innovative public-private partnerships can be referred to as collaborations. After all, it is known that all these associations at the output provide a unique "brand" product, which was created by the efforts of several organizations.

Thus, the technology platform is a communication tool aimed at intensifying efforts to create promising commercial technologies and new products (services), to attract additional resources for research and development based on the participation of all stakeholders (business, science, education, government, civil society) (Fig. 1).

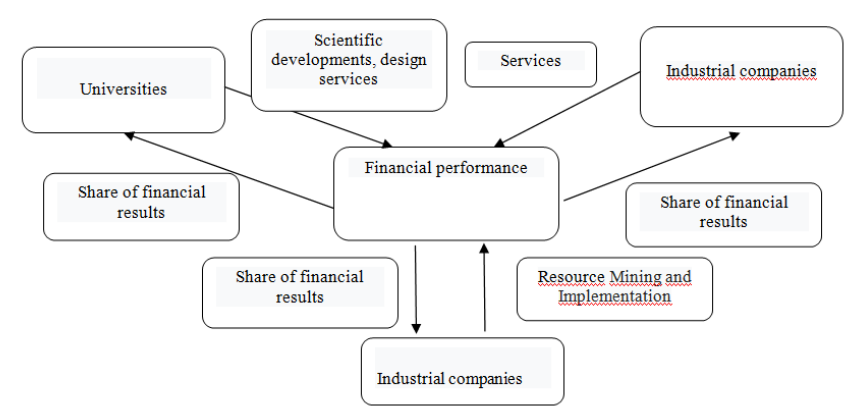

Fig. 1. The scheme of the technological platform

Next, let's consider the collaboration on the basis of innovative public-private partnership (PPP). As a result of the innovative partnership between the state and business, a unique innovative product is also born. Feature of the given model of interaction of participants of the innovative process is the fact that revenues from innovative ideas and technology transfer are given to all participants of the process of creating innovation: governments and scientific institutions in the form of revenues from the implementation and financing of innovative process and business structure, which as a result get the solution by using innovative technologies (development, services).

Another model of collaboration arises based on strategic scientific alliances. Considering the goals of creating strategic 
By participating in a simple partnership agreement, each of scientific alliances, we focus on such elements of the innovation process as the organization of complex scientific research, the creation of network information technologies and technology transfer. We believe that these components of innovation activity are currently the most problematic areas for the creation of collaborations, and require the search for new organizational and legal forms of activity (Fig. 2).

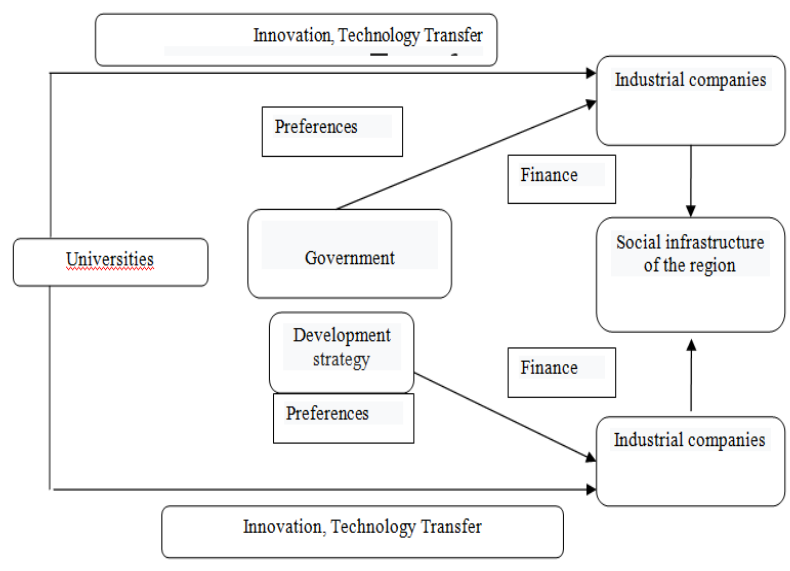

Fig. 2. Scheme of innovative public-private partnership

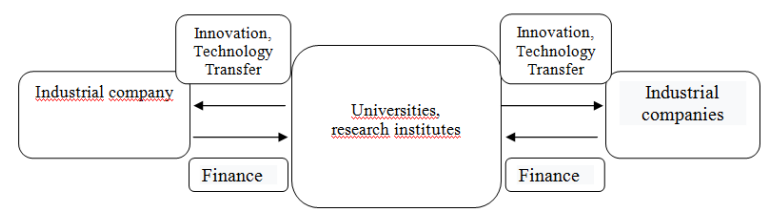

Fig. 3. Scheme of the strategic scientific alliance

The considered models of agreements in collaborations are more efficient to build on the basis of a multilateral cooperation agreement in the form of a simple partnership agreement.

Under a simple partnership agreement (joint venture agreement), two or more persons (partners) undertake to combine their contributions and act together without forming a legal entity to make a profit or achieve another purpose not contrary to the law.

A simple partnership agreement (joint venture agreement) is an agreement between two or more persons (partners) who undertake to combine their contributions and act together without forming a legal entity to make a profit or achieve another goal that does not contradict the law. Thus, a simple partnership agreement can be a multilateral transaction and does not imply the formation of a new legal entity [18].

Only individual entrepreneurs and (or) commercial organizations can be parties to a simple partnership agreement concluded for entrepreneurial activity [19].

Features of the contract of the simple partnership concluded for implementation of joint investment activity (investment partnership) in Russia are established by the Federal law "About investment partnership" [20]. the partners is free to simultaneously conduct the usual economic activities: to conclude contracts, perform works, provide services, and carry out production and / or sale of goods not in the interests of the partnership. Moreover, each of the partners is free to participate in another Contract of simple partnership.

Thus, in case of simultaneous implementation of activity in self-interest and in interests of partnership, the participant of simple partnership shall provide separate accounting of the income and expenses, property. We also recommend that each partner shall open a separate current account to control income and expenses in the framework of joint activities. It is also possible in a simple partnership agreement to provide that any default actions of a partner are actions in the interests of the partnership.

Partners, each possesses any asset, unite the contributions under the agreement of simple partnership. After that, each of the partners implements the function entrusted to him (buys, produces, sells, mounts). Income and expenses of joint activities are recorded in the "common pot", the financial result - the profit of the partnership - is determined at least once a quarter and is distributed between the partners.

In this case, it is necessary to single out one of the partners leading common affairs.

The partner can have three different statuses:

- participant, leading accounting of common property of partners [21];

- participant, leading common affairs on behalf of all partners [22];

- participant who keeps a General record of transactions subject to VAT in accordance with article 174.1 of the Tax Code [23].

In some cases, namely with the participation of the state as one of the beneficiaries, it would be appropriate to conclude a concession agreement. Under such an agreement, one party (the concessionaire) undertakes at its own expense to create and (or) reconstruct the property determined by this agreement (real estate or real estate and movable property, technologically related and intended for the implementation of activities provided for in the concession agreement [24].

Collaborations as associations of economic entities (organizations) were considered above. However, in the business environment, there are other forms of collaboration.

These are various associations of employers and trade unions, professional societies, networking clubs and interest clubs, etc. All these organizations serve primarily for the exchange of knowledge and experience in certain activities.

There is no doubt that one of the main forms of collaboration is project activity. After all, it is known that in the project people gather once, and just for the implementation of any idea. The difference between this collaboration is a clear allocation of goals and stages of implementation with 
the european aerospace research area," Technological Forecasting and Social Change, vol. 94, 2015, pp. 21-43.

specific deadlines and other attributes inherent in the project activity.

\section{CONCLUSION}

The main findings of the study include the following:

1. An expanded understanding of the collaboration is presented, as any association of various actors in order to obtain some benefits by creating a new business process, new idea, new product or service. It is shown that the participants of the collaboration can be not only organizations, but also executive authorities, which can also achieve their goals and receive public benefits through participation in the collaboration.

2. Identified distinctive signs of collaboration from the usual organization. As the main one, minimization of legal mechanisms for regulating collaborations is shown in comparison with a regular company.

3. Considering the above, as well as the organizational features of building collaborations, it is recommended that you use a simple partnership agreement as the optimal legal form for creating a collaboration between legal entities. The main advantage of this form is the possibility of creating a joint business without the formation of a single legal entity. Moreover, such an agreement will allow participants in collaborations to visualize their benefits from participating in the association.

\section{REFERENCES}

[1] A.V. Babkin, E.A. Baikov, "The Collaboration of industrial and creative clusters in the economy: essence, forms, features," Scientific and technical Bulletin of the St. Petersburg state Polytechnic University. Economics, vol. 11(4), 2018, pp. 141-164.

[2] T.A. Burganov, "Scientific communication and cooperation: from "letters to friends" to collaboration," Herald of Economics, law and sociology, vol. 1, 2013, pp. 207-211.

[3] G.M. Olson, A. Zimmerman, N. Bos, Scientific Collaboration on the Internet, 2008, p. 406.

[4] R. Belderbos, M. Carree, B. Lokshin, J. Fernandez Sastre, "Intertemporal patterns of R\&D collaboration and innovative performance," The Journal of Technology Transfer, vol. 40(1), 2015, pp. 123-137.

[5] L. Biggiero, P.P. Angelini, "Hunting scale-free properties in R\&D collaboration networks: selforganization, power-law and policy issues in
[6] A.M. Thomson, J.L. Perry, "Collaboration Processes: Inside the Black Box," Public Administration Review, vol. 66(1), 2006, pp. 20-32.

[7] N.V. Smorodinskaya, "Network innovation ecosystems and their role in the dynamization of economic growth," Innovations, vol. 7, 2014, pp. 27-33.

[8] S.P. MacGregor, T. Carleton, Sustainable Innovation. Collaboration Models for a Complex World, 2012, p. 172.

[9] E.I. Inshakova, A.Yu. Voloshina, "Megadate-centers as elements of the infrastructure of the global innovation network," Economics: theory and practice, vol. 2(32), 2014, pp. 3-7.

[10] N.V. Smorodinskaya, Globalized economy: from hierarchies to network structure, 2015, p. 344.

[11] O.G. Tihomirova, "Enterprise collaboration and interoperability: the solution to the problem of self-organization of socio-economic systems," Fundamental research, vol. 9(5), 2014, pp. 1082-1086.

[12] E.A. Baikov, L.R. Khakimova, "Collaboration of brands as an effective tool of innovative processes of modern economy," St. Petersburg economic journal, vol. 3, 2018, pp. 39-46.

[13] R. Coase, Firm, market and law, 1993.

[14] V.M. Vinichenko, P. Karacsony, A.V. Kirillov, "Discrimination of talents in organization: sociological analysis," Economic and Social Development: Book of Proceedings. Varazdin Development and Entrepreneurship Agency, 2017, pp. 215-227.

[15] Williamson, The Economic Institution of Capitalism. Firms, Markets, Relation Contracting, 1985, pp. 68-72.

[16] M. Hansen, Collaboration. How to move from competition to cooperation, 2017, p. 288.

[17] N.V. Vasilenko, "Collaboration: institutional characteristics and management capabilities," Strategies and tools of economic management: sectoral and regional aspect Proceedings of the VI International scientific and practical conference, 2016, pp. 14-18.

[18] The civil code of the Russian Federation (part two) from 26.01.1996 N 14-FZ (as amended on 18.03.2019, Rev. from 03.07.2019, CH. 55.

[19] The civil code of the Russian Federation (part two) from 26.01.1996 N 14-FZ (as amended on 18.03.2019, Rev. from 03.07.2019), Art. 1041.

[20] Federal law "On investment partnership" dated 28.11.2011 vol. 335-FZ (edition of 21.07.2014).

[21] The civil code of the Russian Federation (part two) from 26.01.1996 N 14-FZ (as amended on 18.03.2019, Rev. from 03.07.2019, item 2 of Art. 1043.

[22] The civil code of the Russian Federation (part two) from 26.01.1996 N 14-FZ (as amended on 18.03.2019, Rev. from 03.07.2019, item 2 of Art. 1044.

[23] The tax code of the Russian Federation (part two) of 05.08.2000 N 117FZ (ed. of 29.09.2019) (with ed. and extra, of course. effective from 01.11.2019), article 174 .

[24] Federal law of 21.07.2005 N 115-FZ "on concession agreements" (ed. of 27.12.2018), Article 3. 